\title{
A Quick Dielectric Method to Determine Insitu Soil Water Content for Precision Water Use under Sustainable Agricultural Practices
}

\author{
Bandi Hermawan ${ }^{\#}$ Edwin Suparjo ${ }^{\#}$, Kanang S. Hindarto ${ }^{\#}$, Romeo Silalahi ${ }^{\#}$, Faiz Barchia ${ }^{\#}$ \\ ${ }^{\#}$ Department of Soil Science, University of Bengkulu, Jalan WR. Supratman, Bengkulu, 38178, Indonesia \\ E-mail: bhermawan@unib.ac.id
}

\begin{abstract}
Precise water use systems under sustainable agriculture may only be achieved if in-situ soil water content and availability of the plant can be measured quickly. Soil water content can be determined directly using the gravimetrical method by calculating the loss of water when the soil dries out, and indirectly by measuring other variables from which soil water can be calculated. The indirect methods have some advantages when compared to the direct gravimetrical method because measured; non-destructive soil water data are available instantly. Soil dielectric properties have strong relationships with soil water content and have been used widely as indirect methods of soil water determination, but the cost of the available instrument is too expensive for small-scale farmers. Two studies were conducted in 2011 and 2015 to develop a quick, cheap method to determine in-situ soil water content and precise water use by crops. The method applied a non-linear relation between soil water content $\left(\theta\right.$, in $\left.\mathrm{gg}^{-1}\right)$ and soil electrical impedance $(Z$, in $k \Omega)$ as follows: $\theta=a \cdot Z^{b}$ where a and $b$ are constants. Parameter $Z$ showed a good predictor for soil water content $(R \geqslant 0.90)$ therefore can be used to determine soil water content in the field quickly. The dielectric method has been successfully used to determine the water balance in the vegetated soils, in wich changes in soil water content caused by daily rainfall as low as 10 $\mathrm{mm}$ was detected up to the depth of $60 \mathrm{~cm}$. The method was also successfully capable of calculating the amount of water used by palm oil nursery grown in media with different levels of soil organic matter.
\end{abstract}

Keywords — dielectric method; in-situ soil water; sustainable agriculture; water use

\section{INTRODUCTION}

Soil water plays important roles in sustainable agricultural production because it controls many aspects of crop growth such as plant evapotranspiration, nutrient movements from soil solution to the root surface, and metabolism processes in the plant cells. Plant availability of soil water induced through seasonal changes and a growing degraded land throughout the west coast areas of Sumatera Island is expected to increase uncertainty about the sustainability of irrigated agricultural land in Bengkulu, Indonesia. Precision irrigation is required when producers need to adopt water use efficiency and conservation for providing future sustainability of agriculture. Irrigation water use controls the total crop yields while total applied water is related to the cost of sustainable agricultural practices [1]. Precise water use and irrigation systems under sustainable agriculture may only be achieved if in-situ soil water content and availability of the plant can be determined quickly and the amount of irrigation water added to the soil profile can be calculated accurately. The availability of instant information on soil water content along with local weather station is a key to support water saving features when irrigation water is applied according to the demand of water by soil [2].
In the last two decades, the gap between irrigation water supply and demand under agricultural practices increases significantly as a consequence of increasing rates in food consumption and population growth. The gap may be reduced by looking for new water resources around the agricultural fields or by reducing the loss of water use. Since searching for new water sources can be very expensive and difficult to conduct, precision water use efficiency in agricultural practices seems to be the most effective way to reduce the gap [3]. Various efforts have been taken by researchers worldwide to improve soil water use efficiency in agricultural soils, either using soil stabilizing agents such as organic materials to increase the water holding capacity of soil [4] or applying soil moisture sensor controllers for irrigation adequacy and scheduling efficiency [5]. In most part of Indonesia, the cost for water use efficiency strategy can be minimized when rates of precipitation are high during the rainy seasons such as occurs in the November to February growing periods [6].

The first step of increasing water use efficiency strategy for crop production under sustainable agricultural practices is to determine the actual crop water requirement. It can be calculated from agrometeorological parameters including the amount of evapotranspiration water during crop growth [7]. 
The next step is to determine the amount of soil water availability to crops to fulfill the actual requirement of soil water by the agricultural plant. Soil water availability is calculated by subtracting the soil water content at the plantpermanent wilting point from that at field capacity conditions. It can be concluded that the key to precision soil water use under sustainable agricultural practices is how accurate and quick the water content can be determined in the field.

Soil water content can be determined directly using the gravimetrical method by calculating the loss of water when the soil dries out, and indirectly by measuring other variables from which soil water can be calculated. A conventionally gravimetric method for determining soil water content uses soil samples, requires a lot of laboratory works, and spends at least 24 hours to get the data [8]. Despite high accuracy and has been used to standardize all indirect methods, this particular direct technique may raise into problems when dealing with numerous data of soil water content or when soil water in such area in the field needs to be monitored periodically. The use of the gravimetric method is also limited when soil water measurements are conducted in the area not subjected to soil disturbance such as highly dense cash cropping land. Soil disturbance as required for the gravimetric procedure will cause the loss of crop yields. In this case, a quick and simple indirect method of soil water content determination in the field is required due to the inefficiency of the gravimetric method [9].

Indirect methods for soil water determination are widely used and have some advantages when compared to the direct gravimetrical method because measured, and non-destructive soil water data are available instantly [10]. Several waterrelated variables have been measured elsewhere in previous studies to predict soil water content under a large area of agricultural practices. Neutron radiography properties in the soil have long been used by many researchers to determine in-situ soil water content [11]. However, the variables have some disadvantages for determination of soil water content in the small-scale and shallow rooting zone of agricultural practices. Although the neutron variables can be used to monitor landscape-scale soil water content accurately, they are unable to measure all water particularly that close to the soil surface [12].

Other researchers have used some electrical properties to estimate soil water content in the field. The composition and proportion of solid, liquid and gas components in soil control much natural behaviour, some of which are electrical characteristics of the soil. The possible use of electrical properties for determination soil water content in the field had been proven theoretically by Friendman [13]. When the electrical alternating current (AC) travels through a soil column, and there is a presence of opposition to the current in the soil column, it results in a drop in voltage amplitude across the column for a given current. The travel time of voltage pulse along a parallel transmission line inserted into the soil is capable of measuring water content up to the soil surface [14], but the device called Time Domain Reflectometry (TDR) is very expensive, and the small-scale farmers can hardly have it for precision water use and irrigation. Therefore, a simple and cheap instrument applying other electrical variables is needed to quickly determine soil water content in the field at an affordable cost [15].

A measure of opposition to alternating current in soil column is called electrical impedance, or characteristic impedance, or simply impedance of soil. Our study in monitoring soil water content on corn land measures the electrical impedance as a predictor for soil water content [10]. When the circuit is driven with direct current (DC) there is no distinction between impedance (symbol Z) and resistance (symbol R); the latter can be thought of as impedance with zero phase angle, and both of them have the same units (ohm, $\Omega$ ). The meaning of electrical impedance can be understood by substituting it into Ohm's law [16]. Just as impedance extends Ohm's law to cover AC circuits, other results from DC circuit analysis, such as voltage division and current division, can also be extended to AC circuits by replacing resistance with impedance.

\section{MATERIALS AND METHODS}

\section{A. Probe Design and Calibration for Electrical Impedance Measurements}

The proposed instrument used in these studies, called a dielectrometer, was designed to measure the electrical impedance $\mathrm{Z}$ of soils. Parameter $\mathrm{Z}$ was calculated by the instrument from several variables installed in the device such as voltage input resulted from a sinusoidal voltage generator, voltage output, and resistors. The instrument was also occupied with a couple of probes (+) and (-) connected to soils at certain depths; the measured $\mathrm{Z}$ values appeared on the LCD screen of the device. The $\mathrm{Z}$ values were then used to predict soil water content under two consecutive field studies.

Two studies were conducted during the rainy period of 2011 and 2015. A quick dielectric method to determine insitu water content of study soils followed a nonlinear model of

$$
\theta=\mathrm{a} \cdot \mathrm{Z}^{\mathrm{b}}
$$

where $\theta$ (in $\mathrm{gg}^{-1}$ ) is soil gravimetric water content, $\mathrm{Z}$ (in ohm) is electrical impedance, $a$ and $b$ are constants, as found in the previous study [17]. Prior to $\theta$-predicting $\mathrm{Z}$ measurements in both studies, the dielectrometer device was calibrated in the laboratory to enable the conversion of measured $\mathrm{Z}$ values into soil water content using appropriate constants a and $b$. The calibration was required because the $\theta-Z$ relations resulted from the device varied with soil characteristics [15]. Therefore $\mathrm{a}$ and $\mathrm{b}$ constants should be determined prior to $\theta$ prediction for each in-situ study soil.

In the 2011 study, two undisturbed soil samples for the water balance study were taken from the depths of 0-30 and $30-60 \mathrm{~cm}$, respectively, using core soil samplers. The samples were saturated by soaking them in free water four 24-hours, in which the surface level of water was maintained at about $2 \mathrm{~cm}$ below the surface of soil samples. This saturation technique allowed the pore spaces of soil were filled with water without leaving any entrapped air inside the soil. The full saturation condition of soil samples was needed in order to get a good model to calibrate the readings of the instrument and converse them into soil water content. The saturated soil samples were then weighed to provide total porosity as well as the gravimetric water content of the 
saturated soil. The $\mathrm{Z}$ values were then recorded from the device inserted into the soil samples, while the gravimetric water content was calculated from the difference between wet and oven-dry soil samples.

Porewater from saturated samples was extracted by allowing the samples to evaporate under room temperature. After 24-hours of evaporation, soil samples were weighed, and the soil electrical impedance was measured using dielectrometer. The soil samples were reevaporated for another 24-hours, then weighed and the electrical impedance was measured as conducted under saturated condition. The evaporation-measurement cycles were repeated every 24hours until the gravimetric water content of soil samples were approximately at the wilting point condition. Soil samples were oven-dried at $105{ }^{0} \mathrm{C}$ for about 48 -hours, ovendry soil samples were then weighed to calculate soil water content $\theta$ for each measurement.

Similar laboratory calculations of $a$ and $b$ constants were also conducted on soil samples taken from the 2015 study soils. The calibration was conducted on repacked soils in the polybags prior to the plantation of palm oil nursery. Relations between $\theta$ and $\mathrm{Z}$ measured from the soil samples were analyzed using Equation 1 to get constants $\mathrm{a}$ and $\mathrm{b}$ for each soil sample used in the 2011 and 2015 studies. Equation 1 was then ready to be applied for in-situ soil water content by measuring $\mathrm{Z}$ in the field for 2011 study and in repacked soils for 2015 study.

\section{B. Insitu Soil Water Measurements for Water Balance}

In the 2011 study, soil electrical impedance Z was measured quickly using a digital device named dielectrometer as shown in Figure 1. A couple of extension probes containing parallel wire transmission lines in length of $40 \mathrm{~cm}$ was prepared for electrical impedance measurements. The lowest $30 \mathrm{~cm}$ parts of wire lines were left uncovered, inserted vertically into the soil to a depth of $30 \mathrm{~cm}$. Therefore, the transmitting lines were in contact with soil, leaving the rest of $10 \mathrm{~cm}$ rubber-covered lines standing above the soil surface. Another probe containing $70 \mathrm{~cm}$ length of wire lines was prepared similarly to the first probe, in which the lowest $30 \mathrm{~cm}$ parts of lines were left uncovered with rubber, inserted into the soil up to a depth of $60 \mathrm{~cm}$. This method allowed us to measure $Z$ values at the depths of 0-30 and 30-60 $\mathrm{cm}$ for 40 and $70 \mathrm{~cm}$ lengths of wire lines, respectively.
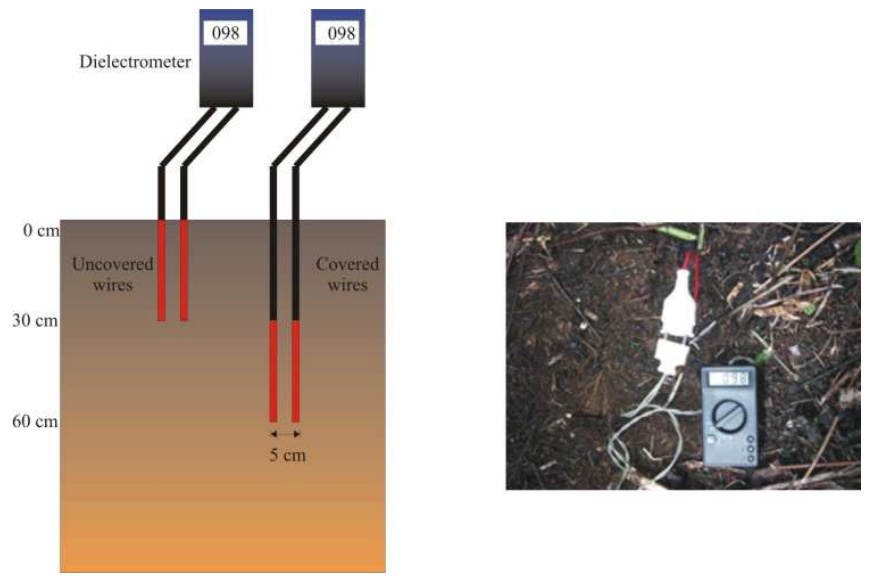

Fig. 1 Schematic probes design (left) and their installation in the field (right) for the water balance study
The probe (+) and probe (-) existing at the dielectrometer device were connected to the ends of paired wire lines above the soil surface, the electrical alternating current (AC) was injected into the soil at a frequency of $1 \mathrm{kHz}$ by pushing the "on/off" button on the device, the electrical impedance $\mathrm{Z}$ of soil was then read from the LCD screen in the unit of kiloohm $(\mathrm{k} \Omega)$. The $\mathrm{Z}$ values were recorded after the numbers appearing on the device LCD screen were in an idle condition indicating the average $\mathrm{Z}$ had been achieved. Soil water content was calculated using Equation 1, in which constants $\mathrm{a}$ and $\mathrm{b}$ had been determined earlier from the laboratory measurements on the same soils.

The extension probes were inserted into the soil to the depths of 0-30 and 30-60 cm, respectively, in the steep land covered by shrubs. Measurements of $\mathrm{Z}$ values were conducted every second day to allow significant changes in soil water content in both depths under field conditions. The $\mathrm{Z}$ values were measured at the depths of $0-30$ and $30-60 \mathrm{~cm}$ using the newly designed dielectrometer device; the measured $\mathrm{Z}$ values were converted into soil water content using Equation 1 by applying $a$ and $b$ values obtained from the laboratory calibration for the $0-30$ and $30-60 \mathrm{~cm}$ depths, respectively.

At the same time of $\mathrm{Z}$ measurements, rainfall was measured by collecting it in a rain gauge consisting a scaled cylinder (in millimeters). A funnel was placed on the top of the gauge, rain water that was caught in the funnel then run down into the cylinder below. The volume of rain inside the cylinder was recorded and divided by the area of the funnel to get the depth of rainfall during the two-days period. Rainfall data were used to calibrate the daily soil water changes as predicted by Equation 1. Predicted values of soil water content and rainfall were plotted against the dates of measurements to evaluate the sensitivity of the proposed method to the soil wetness after rainfall.

\section{Insitu Soil Water Measurements for Precision Water Use}

The 2015 study was conducted to calculate the amount of water used by palm oil nursery grown on polybags containing loamy sand soils treated with different levels of organic matter. Six doses of organic matter applied to growing media prior to $\mathrm{Z}$ measurements were equal to $0,2,4$, 6,8 and 10 ton $\mathrm{ha}^{-1}$. The $\mathrm{Z}$ values were measured daily from December 2014 to February 2015 using the dielectrometer, then converted into the soil water content using Equation 1 as in the 2011 study. Daily changes in soil water content following soil discharge periods were used to calculate the amount of water used by the plants during their growth in the study period.

When soil water content dropped to such a value approaching the permanent wilting point, approximately when the $\mathrm{Z}$ values were about $3.0 \mathrm{k} \Omega$ or higher, water was added to soils in the polybags to increase soil water content up to the field capacity conditions. The $\mathrm{Z}$ values were measured again on the wet soils to allow the prediction of water loss for the next discharged periods by subtracting Zequivalent water content at wet and drier conditions. Rainfall was also recorded during periods of the $\mathrm{Z}$ measurements using the rain gauge to calibrate the amount of water use as calculated from the dielectrometer measurements. 


\section{RESULTS AND DISCUSSION}

\section{A. A Nonlinear Model of $\theta-Z$ Relations}

Equation 1 indicated that soil water content tended to decrease more significantly with increasing $\mathrm{Z}$ when the values of $Z$ were low. However, the change in water content became less significant at higher $\mathrm{Z}$ values. This power model resulted in better curves, as shown by higher values of correlation coefficients when compared to the exponential growth curves usually used to predict the growth phenomena in agricultural and other natural interests [18]. By relating sets of $\mathrm{Z}$ and $\theta$ values resulted from the laboratory experiments, the average $a$ and $b$ were obtained for study soils, and both constants were then applied to Equation 1 for Z-to- $\theta$ conversions under field measurements.

Results on the model calibration in the laboratory for the 2011 study indicated that constants $a$ and $b$ in Equation 1 were 0.69 and -0.37 , respectively, for both $0-30$ and 30-60 $\mathrm{cm}$ soil depths (Figure 2). Therefore, Equation 1 was written as follows

$$
\theta=0.69 . \mathrm{Z}^{-0.37} \quad \mathrm{R}^{2}=0.91
$$

On the 2015 study, the laboratory calibration resulted in $a$ and $b$ values of 0.27 and -0.41 , respectively (Figure 3 ), and the proposed model for this site was

$$
\theta=0.27 . \mathrm{Z}^{-0.41} \quad \mathrm{R}^{2}=0.90
$$

The Z-to- $\theta$ relations for both calibration measurements were very strong as shown by correlation coefficient values $\mathrm{R}^{2}$ of 0.90 or higher. Equations 2 and 3 were then used to convert the $\mathrm{Z}$ values recorded in the field during the 2011 and 2015 studies.

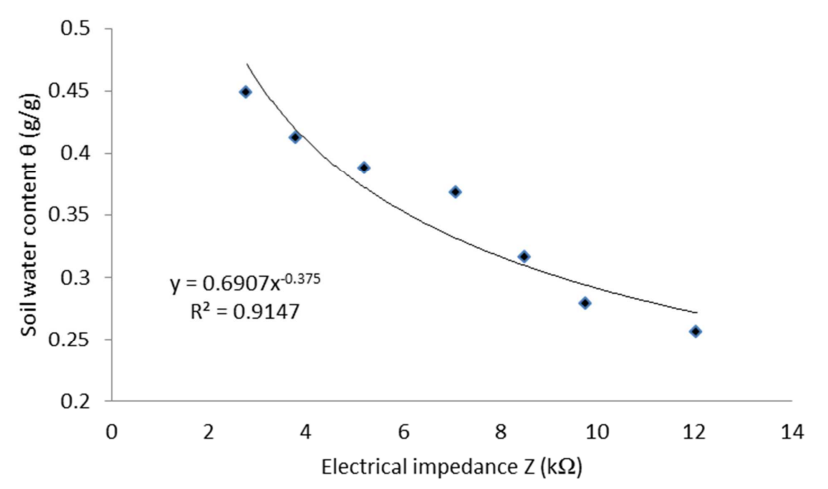

Fig. 2 Values of constants $a$ and $b$ resulted from the laboratory calibration for the 2011 study soils at $0-30$ and $30-60 \mathrm{~cm}$ depths

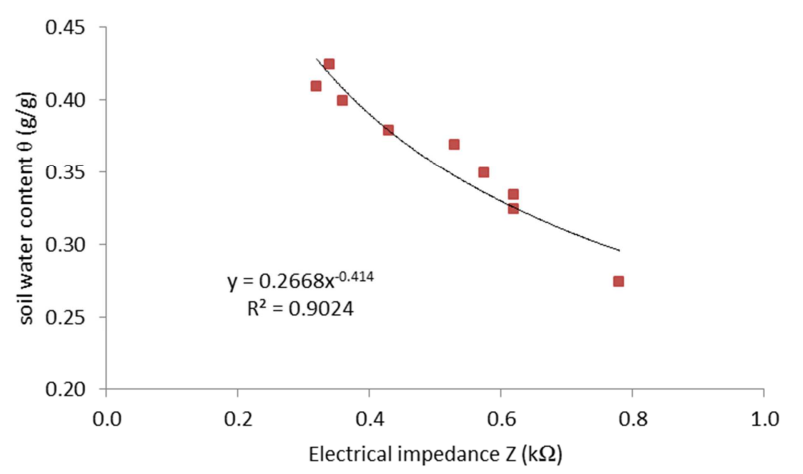

Fig. 3 Values of constants $a$ and $b$ resulted from the laboratory calibration for the 2015 study soils
Constant $a$ seemed to vary more between two study soils compared to constant $b$. The 2011 study was conducted on Inceptisols with higher organic matter content and finer texture than the 2015 study soil of Entisols. These variations might explain why constant $a$ for the 2011 study soil was almost three times higher than that for the 2015 study soil. The relations between soil electrical resistance or impedance and soil organic matter content and clay content have been reported elsewhere [19]. The presence of high organic matter content in the soil, for example, resulted in high soil electrical impedance due to poor electrical conductivity through the soil with high organic material.

The proposed method resulted in these studies worked very well to determine in-situ soil water content with the accuracy of more than 90 percent. It could be used as an alternative technique for determining soil wetness in the field without spending a lot of time and labour as found in the conventionally gravimetric method. However, it was limited to the temporal prediction of in-situ soil water content because constants $a$ and $b$ for Equation 1 needed to be determined prior to the $\mathrm{Z}$ measurements in the field. The calibration of $a$ and $b$ was required because both constants seemed to vary according to several soil properties such texture and organic carbon content as found in our previous study [17]. Therefore, the proposed method worked well for the use of soil water monitoring in which the $\mathrm{Z}$ measurements were conducted periodically at the same points. Paillet et al., for example, has been successful in using dielectrical measurements for the temporal monitoring of forest soils [20].

\section{B. Dielectrical Method for Water Balance Monitoring}

When applied to predict soil water balance during a rainy season in the 2011 study, the proposed method was able to determine temporal changes in soil water content caused by additional precipitation water from daily rainfall. Results showed that a few daily change in soil water content of as low as $10 \mathrm{~mm}$ was detected up to the depth of $60 \mathrm{~cm}$ from the soil surface. Trends of changes in soil water content at 0-30 and 30-60 cm depths followed those of changes in daily rainfall at the same periods of measurements as shown in Figure 4, indicating that rainfall water had reached the soil depth of below $30 \mathrm{~cm}$ about one day following the rain events.

The method resulted in this study was very sensitive to soil wetness variations as indicated by similar movements of daily data points between rainfall and soil water curves in Figure 4. Soil water content predicted using Equation 2 at 030 and 30-60 depths increased significantly following rainfall events and decreased in the absence of rainfall. Changes in soil water content following rainfall events could be explained by the fact that rainfall water entered the soil profile up to the depth of 30-60 cm within two consecutive days from the events, then evaporated quickly following the absence of rainfall. This explanation was similar to the finding of Chen et al. that water evapotranspiration by forest plants was related to the soil wetness and the amount of rainfall [21]. Therefore, the ability of the proposed method in calculating small changes in soil water content after rainfall as found in the 2011 study has been proved by a similar study conducted in different regions. 

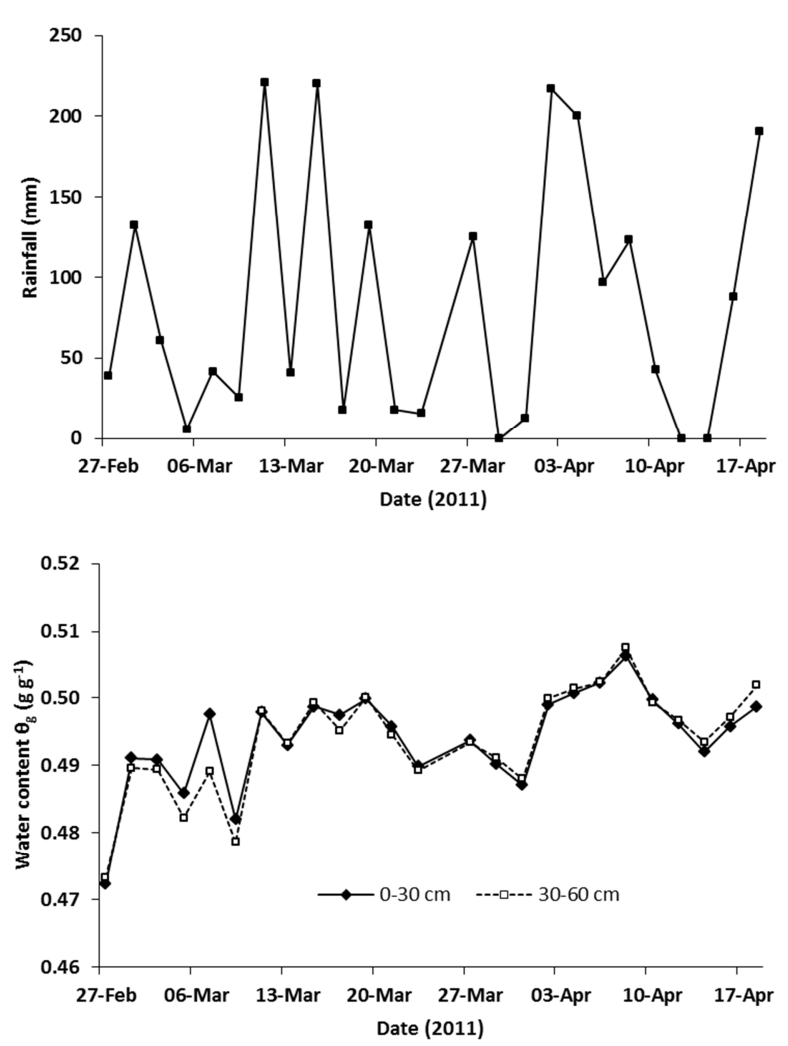

Fig. 4 Temporal soil water content at $0-30$ and $30-60 \mathrm{~cm}$ depths as converted from $\mathrm{Z}$ values using Equation 2 in comparisons with daily rainfall

The sensitivity of the proposed dielectrical method in predicting the relations between soil water content and daily rainfall as shown in Figure 4 would be beneficial to monitor soil water balance on the basis of field data collected from weather stations. Water balance during periods of rainfall and evapotranspiration events in such an area might be predicted from the amount of added rainfall water and rates of loss water from evapotranspiration. The prediction would be useful in some management decisions in agricultural activities such as the time, and the amount of water irrigation must be applied in order to maintain good cropping growth. In particular cases, it would be very important in determining temporal soil water content at a seriously degraded land with restricted water availability when proposed for crop production as reported in our previous study [22]. Therefore, soil water balance might be determined using the proposed quick method of dielectical measurements, using the available data at weather stations, or in a combination of two approaches.

\section{Dielectric Method for Plant Water Use}

The next study in 2015 was to evaluate the accuracy of the proposed dielectrometer method in calculating soil water use during a plant growing period, and analyzing differences in the calculated water uses under different organic matter treatments on planting media. An example of impedance values measured using the proposed dielectrometer and predicted soil water content values was presented in Table 1. The electrical impedance increased up to $0.26 \mathrm{k} \Omega$ during $5^{\text {th }}$ to $7^{\text {th }}$ of January 2015 when there was no rain falling at that period. Increasing impedance was followed by decreasing the predicted soil water content up to $0.04 \mathrm{~g} \mathrm{~g}^{-1}$ during the three-days period of measurements. Assuming there was no water loss through the percolation process, decreased soil water during three days of measuring could only be attributed to evapotranspiration by the plant.

TABLE I

AN EXAMPLE OF Z VALUES AND SOIL WATER CONTENT PREDICTED FROM EQUation 3 During Three ConseCutive Days of MEASUREMENTS ON PALM OIL NURSERY FOR SIX DOSES OF SOIL ORGANIC MATTER (SOM)

\begin{tabular}{|c|c|c|c|c|c|c|}
\hline \multirow{2}{*}{$\begin{array}{c}\text { Date } \\
(2015)\end{array}$} & $\mathbf{0}$ & $\mathbf{2}$ & $\mathbf{4}$ & $\mathbf{6}$ & $\mathbf{8}$ & $\mathbf{1 0}$ \\
\cline { 2 - 7 } & \multicolumn{7}{|c|}{ Measured Impedance $(\mathrm{k} \Omega)$} \\
\hline 5-Jan & 0.81 & 0.81 & 0.71 & 0.72 & 0.72 & 0.85 \\
\hline 6-Jan & 0.86 & 0.89 & 0.76 & 0.76 & 0.77 & 0.91 \\
\hline 7-Jan & 0.99 & 0.99 & 0.87 & 0.98 & 0.93 & 1.05 \\
\hline \multicolumn{7}{|c|}{ Predicted Water Content $\left(\mathrm{g} \mathrm{g}^{-1}\right)$} \\
\hline 5-Jan & 0.29 & 0.29 & 0.31 & 0.31 & 0.31 & 0.29 \\
\hline 6-Jan & 0.29 & 0.28 & 0.30 & 0.30 & 0.30 & 0.28 \\
\hline 7-Jan & 0.27 & 0.27 & 0.29 & 0.27 & 0.28 & 0.26 \\
\hline
\end{tabular}

Results also showed that the proposed dielectric method was successful in calculating the amount of water used by palm oil nursery under various organic matter treatments. As presented in Table 2, the dielectrically predicted water use during a 60-days growing period of palm oil nursery was lowest under the 4 ton $\mathrm{ha}^{-1}$ application of organic matter. An addition of equally 4 ton $\mathrm{ha}^{-1}$ organic matter to soil media for palm oil nursery has saved up to 4 liters of water during two months growth of the plant. Results presented in Table 2 suggested that the proposed method of predicting soil water content was applicable for soil water management in the agricultural fields such as determination of water use efficiency.

TABLE II

ACCUMUlative WATER USE BY PALM OIL NURSERY FOR SIX DOSES OF SOIL ORGANIC MATTER AS PREDICTED FROM EQUATION 3

\begin{tabular}{|c|c|c|c|c|c|c|}
\hline \multirow{2}{*}{ Day } & \multicolumn{7}{|c|}{ Accumulation of Plant Water Use (in L) } \\
\cline { 2 - 7 } & D0 & D1 & D2 & D3 & D4 & D5 \\
\hline 1 & 1 & 1 & 1 & 1 & 1 & 1 \\
\hline 10 & 4 & 5 & 4 & 4 & 4 & 4 \\
\hline 20 & 6 & 7 & 6 & 6 & 6 & 6 \\
\hline 30 & 9 & 10 & 9 & 8 & 9 & 9 \\
\hline 40 & 13 & 13 & 11 & 12 & 13 & 12 \\
\hline 50 & 17 & 18 & 15 & 16 & 18 & 16 \\
\hline 60 & 21 & 23 & 19 & 21 & 23 & 20 \\
\hline
\end{tabular}

Note: D0 to D5 were soil organic matter treatments equaled to $0,2,4,6,8$ and 10 ton ha ${ }^{-1}$

A quick measurement technique for electrical impedance in the soil as found in the current studies promotes the future method of calculating plant water use in the field without taking soil samples as found in the conventional method of determining soil water content. The method has several advantages compared to the conventional one including instant values of soil water content, in-situ instead of laboratory measurements, as well as environmentally friendly procedures in soil water determination. These phenomena seem to be appropriate for sustainable practices for the future generation. Water use efficiency will be an important variable for the future plant production worldwide because it might control some behaviour of crop growth such leaf stomatal conductance [23]. A quick method of calculating water use efficiency is urgently required because water requirement by the plant varies widely and depends on 
many environmental factors such as soil types, as well as types and growing periods of the plant [24]. Therefore, the proposed method resulted in these studies would contribute to the sustainable crop production.

\section{CONCLUSIONS}

The method developed in our studies applied a non-linear relation between soil water content $\left(\theta\right.$, in $\left.\mathrm{gg}^{-1}\right)$ and soil electrical impedance ( $Z$, in $\mathrm{k} \Omega$ ) as follows: $\theta=\mathrm{a} \cdot \mathrm{Z}^{\mathrm{b}}$ where $\mathrm{a}$ and $\mathrm{b}$ are constants. Constants $a$ and $b$ should be determined in the laboratory prior to the field measurements. Therefore, the method was suitable to monitor temporal variations in soil water content. Parameter $\mathrm{Z}$ showed a good predictor for soil water content $(\mathrm{R} \geqslant 0.90)$ therefore can be used to determine soil water content in the field quickly. The dielectric method has been successfully used to determine the water balance in the vegetated soils, in which changes in soil water content caused by daily rainfall as low as $10 \mathrm{~mm}$ was detected up to the depth of $60 \mathrm{~cm}$. The method was also successfully capable of calculating the amount of water used by palm oil nursery grown in media with different levels of soil organic matter. Differences in plant water use between organic matter treatments were also detected very well in these studies.

\section{ACKNOWLEDGMENT}

We would like to thank Andrew, Riyan (undergraduate students at University of Bengkulu), and Bardiono (farmer) for their assistance in the field works.

\section{REFERENCES}

[1] G.D. Schaible, C.S. Kim, and M.P. Aillery, "Dynamic adjustment of irrigation technology-water management in western U.S. agriculture: toward a sustainable future," Canadian Journal of Agricultural Economics, vol. 58, pp. 433 - 461, Dec. 2010.

[2] R.S. Dhakal, G.Syme, E. Andre, C. Sabato, "Sustainable water management for urban agriculture, gardens and public open space irrigation: A case study in Perth," Agricultural Sciences, vol. 6, pp. 676-685, Jul. 2015

[3] K.O. Rauff, and S.A. Shittu, "Determination of evapotranspiration and water use efficiency in crop production," Agricultural Sciences, vol. 6, no. 9, pp. 1058-1067, Sep. 2015.

[4] M. Nyatuame, and S. Nartey, "Effects of cocoa husk powder and cow dung on moisture content and infiltration rate of sandy soil," Int. J. of Soil Sci., vol. 8 no.2, pp. 68-77, 2013.

[5] M.S. McCready, and M.D. Dukes, "Landscape irrigation scheduling efficiency and adequacy by various controll technologies," Agricultural Water Management, vol. 98, pp. 697-704, 2011.

[6] D. Yanti, "The use of solar cell in ground water irrigation to support agricultural cultivation in rainfed field," International Journal on Advanced Science, Engineering and Information Technology, vol. 6 no. 1, pp. 112-115, Feb. 2016. [Online]. Available: http://dx.doi.org/10.18517/ijaseit.6.1.677.

[7] M. Rashmi, and V. Pandey, "Reference evapotranspiration (ETo) and crop water requirement (ETc) of wheat and maize in Gujarat," Journal of Agrometeorology, vol. 17 no.1, pp. 107-, Jun. 2015.
[8] A. Klute, Ed., Methods of Soil Analysis: Part I-Physical and Mineralogical Methods, 2nd ed., Madison, USA: ASA-SSSA. 1986, vol. 9.

[9] A.S. Nadler, S. Desberg, and I. Lapid, “Time domain reflectrometry measurements of water content and electrical conductivity of layered soil columns," Soil Science Society of America Journal, vol. 55, pp. 938-943, 1991.

[10] B. Hermawan, "Monitoring soil water content by measuring electrical properties on corn land," Indonesian Journal of Agricultural Sciences, vol. 7 no.1, pp. 15-22, 2005.

[11] C.L. Cheng, M. Kang, E. Perfect, S. Voisin, J. Horita, H. Bilheux, J.M. Warren, D.L. Jacobson, and D.S. Hussey, "Average soil water retention curves measured by neutron radiography," Soil Science Society of America Journal, vol. 76 no. 4, pp. 1184-1191, Jul. 2012.

[12] T.E. Franz, A. Wahbi, M. Vreugdenhil, G. Weltin, L. Heng, M Oismueller, P. Strauss, G. Dercon, and D. Desilets. "Using CosmicRay Neutron Probes to monitor landscape scale soil water content in mixed land use agricultural systems," Applied and Environmental Soil Science (2016), doi: http://dx.doi.org/10.1155/2016/4323742.

[13] S.P. Friendman, "Statistical mixing model for the apparent dieletric constant of unsaturated porous media," Soil Science Society of America Journal, vol. 61, pp. 742-745, 1997.

[14] G.C. Topp, J.L. Davis, and A.P. Annan, "Electromagnetic determination of soil water content: Measurements in coaxial transmission lines," Water Resources Research, vol. 16, pp. 574-582, 1980 .

[15] A. Mortl, R. Muñoz-Carpena, D. Kaplan, and Y. Li, "Calibration of a combined dielectric probe for soil moisture and porewater salinity measurement in organic and mineral coastal wetland soils," Geoderma, vol. 161, pp. 50-62, 2011.

[16] P. Horowitz, and W. Hill, The Art of Electronics, Cambridge University Press, 1989.

[17] B. Hermawan, "Determination of soil water content by measuring a dielectrical property: a laboratory experiment at various compaction levels," Indonesian Journal of Agricultural Sciences, vol. 6 no. 2, pp. 66-74, 2004.

[18] G.S. Snedecor and W.G. Cohran, Statistical Methods, $7^{\text {th }}$ ed., The Iowa State University Press, USA, 1980.

[19] A.I. Pozdnyakov, P.I. Eliseev, and L.A. Pozdnyakov, "Electrophysical approach to assessing some cultivation and fertility elements of light soils in the humid zone," Eurasian Soil Science, vol. 48 no. 7, pp. 726-734, 2015.

[20] Y. Paillet, N. Cassagne, and J.-J. Brun, "Monitoring forest soil properties with electrical resistivity," Biol Fertil Soils, vol. 46, pp. 451-460, 2010.

[21] L. Chen, Z. Zhang, T. Zha, K. Mo, Y. Zhang, and X. Fang, "Soil water affects transpiration response to rainfall and vapor pressure deficit in poplar plantation," New Forests, vol. 45 no. 2, pp. 235-250, 2014.

[22] B. Hermawan, "Sustainable Agroforestry Models for Proposed Food Production in Post-Mined Land Sites of South Sumatera," International Journal on Advanced Science, Engineering and Information Technology, vol. 6, no. 2, pp. 245-251, 2016. [Online]. Available: http://dx.doi.org/10.18517/ijaseit.6.2.727.

[23] J. Gulías, G. Seddaiu, J. Cifre, M. Salis, and L. Ledda, "Leaf and Plant Water Use Efficiency in Cocksfoot and Tall Fescue Accessions under Differing Soil Water Availability," Crop Science, vol. 52 no. 5 , pp. 2321-2331, 2012.

[24] N. Bafdal, "Rainfall Harvesting as Resources of Self Watering Fertigation System with Various Growing Medias," International Journal on Advanced Science, Engineering and Information Technology, vol. 6, no. 5, pp. 788-792, 2016. [Online]. Available: http://dx.doi.org/10.18517/ijaseit.6.5.1158. 